\title{
REFLECTIONS
}

\section{Helping 'Them': Our Role in Recovery From Opioid Dependence}

David Loxterkamp, MD

Private practice, Belfast, Me

Conflicts of interest: none reported

CORRESPONDING AUTHOR

David Loxtercamp, MD

Seaport Family Practice, PA

41 Wight St

Belfast, ME 04915

dr.loxterkamp@verizon.net

\begin{abstract}
The crisis of opioid addiction in America has been fueled by the diversion of prescription pain pills and the emergence of pure and inexpensive heroin. Until recently, benefits of and access to therapy were limited. This situation changed in 2003 with Food and Drug Administration approval of buprenorphine for the office-based treatment of opioid dependence. Now armed with a potent drug, primary care physicians can treat addicted patients in their own practice and from their own neighborhood, but first we must overcome deficiencies in our training and personal biases about addicts and what they need. This a report of one doctor's progress.
\end{abstract}

Ann Fam Med 2006;4:168-171. DOI: 10.1370/afm.518.

\section{INTRODUCTION}

here is a fire raging in America. Heroin, methadone, and oxycodone dependence are consuming the lives of young people in ways we refuse to fathom.

A decade ago the problem spread from blighted inner-city neighborhoods to the mill towns, fishing villages, and insulated campuses of my home state of Maine. That I did not see it coming can be blamed on my lack of training, but also on raw apathy, wrapped in the blithe belief that it happens only to "them," the welfare moms, deadbeat dads, and troubled youths from broken homes with too much attitude, body piercing, and jail time. Sooner or later the truth hits us, as it did when I first met Maddie.

\section{Madeline}

She agreed to meet me in the emergency department on that February evening in 2003. Madeline had been popular and successful in high school. Now a college sophomore, she found herself addicted to, and withdrawing from, opioids. Exhausted by a third day of intractable vomiting, Maddie accepted hospital treatment with clonidine, promethazine, and intravenous fluids. She was soon well enough to go home, and her parents promised that they would find her a substance abuse counselor.

I had known the family since 1986, when I treated her mother during a miscarriage; the baby did not survive, but the family soon transferred to my care. In July of 1999, I delivered the fourth of their offspring, of whom Maddie had been the first.

She experimented with prescription pain pills in college. Then her boyfriend introduced her to methadone and heroin. She worked 2 jobs to support her habit. She still had dreams of making something of her life. Sadly, she had no thoughts of leaving her boyfriend.

During the next 9 months she was hospitalized repeatedly. Once we transferred her for detoxification at a nearby psychiatric unit; once 
she went to Portland for short-term residential care. Another admission followed a grand mal seizure from drug-induced encephalopathy. Between hospitalizations I saw her in the office and chatted about her studies. I hadn't a clue whether she was still using drugs, even as I wrote a second prescription for nasal impetigo. I made no connection between her addiction and her brother's arrest for trafficking, or the OxyContin I prescribed for her father's back pain.

\section{National Crisis}

Madeline and her peers never had any trouble finding heroin, even in rural Maine. When National Public Radio ran a 5-part series titled Heroin in America in February 2004, it reported from a fishing village 95 miles up the coast from my hometown. Here you'll find the "new" heroin addict: white, nonurban, young. Eighty percent of the inmates in the Washington County jail —as elsewhere in the state-were arrested for alcohol- and drug-related crimes. Many in this blue-collar community became addicted to prescription painkillers first and only later switched to heroin because it was less expensive and more readily available. Much of the heroin comes from Lowell and Lawrence, Mass; it is $80 \%$ to $90 \%$ pure and costs $\$ 5.00$ a packet, cheaper than a 6 -pack of beer.

Alcohol and nicotine are the most abused drugs in Maine, but their use has declined steadily since 1995, when intervention strategies began to target middle schools. Results of the 2002 Maine Youth Drug and Alcohol Use Survey show that 55\% of high school seniors have tried alcohol, whereas 3 in 10 report binge drinking within the past month. ${ }^{1}$ For the first time, marijuana use exceeded cigarette use. Twenty-nine percent of high school seniors reported using marijuana in the past month, $10.7 \%$ used diverted prescription drugs, $2.9 \%$ had tried cocaine, and $1.3 \%$ had tried heroin. Data from the National Drug Intelligence Center suggest that treatment admissions for opioid dependence have skyrocketed in Maine. ${ }^{2}$ From 2000 to 2002, the number of admissions for heroin dependence climbed by $106 \%$; admissions for prescription opioid dependence increased by $80 \%$. The number of drugrelated deaths increased statewide from 33 in 1997 to 90 in 2001.

Self-reporting polls suggest that of the 300 seniors in our local high school, 32 have tried opioid pain pills and 4 have snorted heroin. In the 5 years after their graduation from school, the numbers will soar. None will have difficulty finding drugs, but paying for them is another matter. The street value of their habit will average $\$ 150$ to $\$ 200$ a day. That most of those who seek treatment cannot afford the cost of a weekly office visit, therapy appointment, and pharmacy tab attests to the enormous risks they undertake to finance their addiction.

\section{OUR PROGRAM}

In 2000, the Drug Addiction Treatment Act of 2000 (DATA 2000) created an opportunity (known as a waiver) for qualified office-based physicians to prescribe opioids for opioid dependence. Three years later the Food and Drug Administration (FDA) approved Suboxone, but it came too late for Maddie. I never forgot the agony of her withdrawals, the weariness of her parents with each remission, or the quiet panic I felt seeing my own teenaged daughter in her eyes. It pushed me to begin the process of obtaining a Suboxone waiver ${ }^{3}$ so I could prescribe the drug in my office. Duly licensed physicians not qualified in addiction medicine must apply to the FDA for a waiver. A special Drug Enforcement Administration number is awarded once the doctor completes an approved 8-hour training course, agrees to limit the practice to 30 active patients, and is able to refer them for substance abuse counseling. As of January 2005, a total of 4,234 physicians had been granted a waiver.

Suboxone, manufactured by Reckitt Benckiser Pharmaceuticals, is the proprietary name for a pill that combines buprenorphine and naloxone. Buprenorphine is a partial opioid agonist that-like heroin, methadone, and oxycodone-stimulates the brain's mu (morphine) receptor. Because it has a stronger affinity for the receptor site than full agonists, it displaces opioids already attached. And it is slower to dissociate, remaining active for up to 48 hours. Buprenorphine's agonist effect plateaus at a moderately low dose, above which no additional pleasure or respiratory depression is observed. Naloxone, an opioid antagonist, was combined with buprenorphine to minimize abuse. Ingested sublingually, naloxone has little activity, but intravenous administration antagonizes the action of buprenorphine. This mechanism diminishes its street value as an intoxicant, but it has been used as a bridge to the next heroin fix. All of these qualities make Suboxone an ideal agent for the treatment of opioid addiction. What patients and clinicians quickly grasp is that it works: it prevents withdrawal symptoms, eliminates cravings, and restores regularity to a disjointed life.

In June 2004, a colleague and I began an officebased program for the treatment of opioid dependence. Fifty-four patients have matriculated into the program; 30 remain. Patients sign a treatment contract that requires them to abstain from drugs, attend weekly counseling sessions, and receive medical follow-up with a primary care physician. Most enroll in an intensive outpatient program (IOP), a supportive 
and educational program of group therapy that meets daily for 4 to 6 weeks.

The therapy team meets monthly to discuss program hitches and difficult patients. We negotiate differing philosophies and management styles regarding team rules and the consequences for violating them.

We walk a tightrope between advocating for our patients and enforcing the rules, and we have etched only a few rules in stone. One rule is that we require patients to be in recovery, that is, committed to sobriety. Attendance at counseling sessions is the surrogate marker for that commitment. Patients know they will be discharged if they avoid therapy, divert Suboxone, traffic in illicit drugs, or disrupt the office. So far, bad behavior has not been an issue; most who were discharged from the program failed to attend counseling sessions.

We do not accept only patients who are easy to manage. Many come to us with a history of extended opioid use, chaotic homes, psychiatric comorbidities, or methadone use at a dose of $60 \mathrm{mg}$ or more a day. Only patients with chronic pain who require opioids are categorically denied. We are discovering, however, that the higher patients' risk, the greater their need for intensive therapy and surveillance. Office-based buprenorphine was never meant to replace the methadone maintenance clinic, and each office-based program must abide by its limitations.

Importantly, we do not discharge patients on the basis of a positive urine test. We regard it as only 1 measure of their commitment to sobriety; therefore, patients seldom falsify their urine samples, even without the use of surveillance cameras or direct observation. A positive urine test for any illicit drug is a cause for concern and, in our experience, is the best predictor of future failure. It triggers the need for closer observation, more frequent therapy, or a change in strategy (eg, referral to IOP or residential treatment). Curiously, many of our patients do not consider marijuana use as a contradiction to their recovery. We do and point out that it leads statistically to double the rate of recidivism in our program.

Our typical patient is 20 to 24 years of age, takes $16 \mathrm{mg}$ of Suboxone a day, lives within 20 miles of our office, copes with a psychiatric diagnosis in addition to substance abuse, and remains opioid-free. Our experience shows that treatment failure is associated with positive urine drug tests, a long drive to the office, and lack of insurance. Comorbidity and state assistance are not negative predictors; indeed, state aid pays for the mandatory substance abuse counseling, doctors' visits, and Suboxone (costing \$16 a day).

Perhaps one third of our patients will drop out, another third will fight an uphill battle against their self-defeating social system, and the final third will remain in recovery. On any given day, patients move freely between groups and remain citizens of all.

\section{What Patients Need From Us}

I have been asking my patients taking Suboxone what an earnest physician might do to help them. Most say, "Don't judge." Try to understand the shame they were able to hide before becoming sick or destitute or scared enough to seek help. Many have looted their parents, lied to their spouses, stiffed their employers, or abused themselves and their lovers to nurse their habit. They want what they don't deserve-a second or even 30th chance. This is the strongest rationale for treating opioid dependence in the office: without prejudice or segregation, we attempt to meet a medical need.

I am not suggesting that we suddenly let "them" in our doors. They've been here all along, the invisible addicts, the ones we treated for cellulitis, pelvic infection, functional pain, or preterm labor. What might have we asked more candidly when we found elevated liver enzymes or a positive DNA swab, or during the weeks after the overdose or months after the return from treatment?

At the very least, doctors must be savvy about pain prescriptions. More than 1 week's course of narcotics (including hydrocodone) should require a drug contract. Contracts must be enforced, enforcement requires urine testing. All physicians should have the capacity to perform qualitative drug screening tests in their office and be willing to exercise it. Since our local emergency department lowered its index of suspicion for obtaining urine drug tests, we have admitted 2 more of our own patients into office-based treatment. Clearly the cure will require our combined effort. For the estimated 2.5 million prescription-dependent patients and 800,000 heroin abusers in the United States, ${ }^{4}$ their undertrained primary and emergency physicians are the only addiction specialists they will know.

\section{Sheila}

Sheila is typical of patients who fall (or crawl) through cracks in the health care system. She began smoking marijuana when she was 12 years old. At 18 years, she received her first hydrocodone prescription in the emergency department after an automobile accident and became addicted. Five years ago, she attempted suicide by overdosing on whatever drug she could ingest ; both methadone and cocaine were found in her urine. Nevertheless, Sheila was given narcotic pain relievers during 12 of her 18 subsequent visits to the same emergency department. She was hospitalized 6 times: 5 for surgical procedures requiring postoperative pain control, the last for unexplained abdominal pain. 
The only constancy in her life was addiction: she snorted up to 1 dozen OxyContin a day through 3 pregnancies, 2 marriages, and a spate of failed jobs that never quite supported her habit. She came to see my partner to request narcotics for chronic back pain. He ordered a magnetic resonance imaging scan, requested old records, and, on his way out of town, sent her to see me. So today, as I fell further behind in the schedule, I listened to Sheila's convoluted tale, signed a narcotics contract, and tested her urine: positive for methadone and tetrahydrocannabinol. When I asked if she really wanted hydrocodone or would prefer to receive treatment for drug dependence, she buried her head, closed her eyes, and wept.

Sheila agreed to join the Suboxone program. On the second day of induction, she spoke excitedly of her liberation: no longer was she enslaved to seeking, taking, hiding, or withdrawing from drugs. She never quite made it to counseling, however. She lied to me about the supportiveness of her husband, who verbally abused her and forced her to flee to a homeless shelter. Her mother was not eager to see her in recovery; grandma might lose the control and income that came with custody of Sheila's children. And Sheila could not free herself from old contacts and routines and the lure of a kind of happiness-however brief, at whatever cost - that she had only ever found on drugs. She was "lost to follow-up" within 3 weeks.

\section{CHALLENGES}

Yet we keep trying, with high hopes and tempered expectations. Addiction medicine challenges the privilege and patience of the family physician. We learn to rely on a new form of trust, one based on verifiable action. We try not to take dishonesty personally. Two of my colleagues "fired" their patients when they discovered that they were in our treatment program and had been using prescription narcotics to supplement their habit. "How could he lie to me like that?" one ranted. Because he was addicted! Lying is a survival skill that conceals the habit, debt, and criminal activity of the addict.

Patients taking Suboxone are often more difficult than the average. They have a higher rate of no-shows and use of welfare. Nearly one half carry Axis I diagnoses, such as depression, bipolar disorder, anxiety, obsessive-compulsive disorder, or attention-deficit disorder; thus, they are (or should be) taking unfamiliar drugs prescribed in that parallel universe of mental health. Many are homeless, in trouble with the law, unem- ployed, products of family chaos, and living on the social rim. They require frequent telephone calls and referrals to other health care professionals, adjustments in the treatment plan, and intensive teamwork.

In the treatment of drug abuse, there is no star of the show. Doctors who participate in their patients' recovery will play only a small part and accept long odds against success. Counseling, offered with intensity and frequency and in groups, holds the key. But our prescription for Suboxone is the carrot for counseling; our drug screening provides a test for treatment. The team approach to substance abuse resembles the more successful models we use to treat all chronic diseases.

I am no addiction specialist. But it is gratifying to be part of the solution for the national narcotics crisis instead of fueling it with poorly managed prescriptions It is thrilling to hear patients tell of their escape from drug addiction, one that precludes any real commitment to spouse, family, or boss. It is a relief to see professional attitudes bend to welcome opioid-dependent patients with their attendant comorbidities and social liabilities.

The Hippocratic oath once inspired us as physicians to use our "power to help the sick to the best of our ability." With Suboxone, this power now extends to the treatment of opioid dependence by primary care physicians. It takes more than a prescription to create lasting change, counseling options and strong community alliances are essential. So, too, is our unshakable conviction that there is no "them" in the general public we have vowed to serve.

To read or post commentaries in response to this article, see it online at http://www.annfammed.org/cgi/content/full/4/2/168.

Key words: Buprenorphine; opiate dependence; physician-patient relations; drug abuse; substance-related disorders; mental health

Submitted May 27, 2005; submitted, revised, August 28, 2005; accepted September 15, 2005.

\section{References}

1. Maine Office of Substance Abuse. Maine Youth Drug and Alcohol Use Survey (MYDAUS). 2002 Results. Available at: http://www.maine. gov/dhhs/bds/osa/data/mydaus/mydaus2002.htm.

2. National Drug Intelligence Center. Maine Drug Threat Assessment Update. August 2003. Available at: http://www.usdoj.gov/ndic/ pubs5/5764/heroin.htm. Accessed February 8, 2006.

3. US Department of Health and Human Services. Substance Abuse and Mental Health Administration. Center for Substance Abuse Treatment. Buprenorphine: Physician Waiver Qualifications. Available at: http:// buprenorphine.samhsa.gov/waiver_qualifications.html.

4. American Academy of Family Physicians News Department. Wanted: FPs with buprenorphine prescription waivers. FPReport Online. 2004;10. Available at: http://www.aafp.org/fpr/20040400/6.html. 